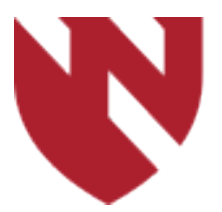

October 2021

\title{
Intravascular B-Cell Lymphoma Presenting as Cortical Venous Thrombosis
}

\author{
Praveen Hariharan \\ University of Nebraska Medical Center \\ Mridula Krishnan \\ University of Nebraska Medical Center \\ Timothy Greiner \\ University of Nebraska Medical Center \\ Catalina Amador \\ University of Nebraska Medical Center \\ Marco Gonzalez-Castellon \\ University of Nebraska Medical Center
}

Tell us how you used this information in this short survey.

Follow this and additional works at: https://digitalcommons.unmc.edu/gmerj

Part of the Higher Education Commons, and the Medicine and Health Sciences Commons

\section{Recommended Citation}

Hariharan, P., Krishnan, M., Greiner, T., Amador, C., , Gonzalez-Castellon, M. Intravascular B-Cell Lymphoma Presenting as Cortical Venous Thrombosis. Graduate Medical Education Research Journal. 2021 Oct 04; 3(1). https://digitalcommons.unmc.edu/gmerj/vol3/iss1/23 
Intravascular B-Cell Lymphoma Presenting as Cortical Venous Thrombosis

Creative Commons License

(c) 1 (1) (अ)

This work is licensed under a Creative Commons Attribution-Noncommercial-No Derivative Works 4.0 License. 
Methods: Patients with isolated distal fibula fractures were prospectively enrolled between 2018 and 2020. Patients with MCS $<4 \mathrm{~mm}$ on standard NWB ankle radiographs with isolated distal fibula fractures had gravity stress views obtained in the emergency department. Patients were placed in a walking boot and instructed to weight-bear as tolerated (WBAT). WB radiographs were obtained one week later. If the MCS was $>4 \mathrm{~mm}$ on followup WB radiographs, surgical intervention was performed. If MCS was $<4 \mathrm{~mm}$, then management continued with WBAT in a walking boot. AOFAS scores were obtained at three months and six months for all patients.
Results: 44 patients met inclusion criteria for analysis, 22 patients had a MCS $>4 \mathrm{~mm}$ on initial gravity stress views. All 22 of those patients, as well as the remaining 22 patients, continued to show MCS $<4 \mathrm{~mm}$ on all follow-up weight-bearing radiographs up to six-month follow-up while using our novel WBAT protocol. The average AOFAS scores were comparable for both groups.

Conclusion: Instructing patients to WBAT in a walking boot is a viable method to determine stability in isolated distal fibula fractures. Given that all patients at subsequent follow-up had a MCS $<4 \mathrm{~mm}$, including those who widened on initial stress radiographs, an immediate WB protocol may offer an improved indication of ankle stability when compared to the current gold standard stress radiographs. Finally, we saw excellent patientreported outcomes utilizing our immediate weight-bearing protocol.

https://doi.org/10.32873/unmc.dc.gmerj.3.1.035

\author{
Guillain Barre Syndrome as a Complication of COVID-19: A Systematic Review \\ Mohammad Aladawi ${ }^{1}$, Mohamed Elfil', Baha Abu-Esheh², Deaa Abu Jazar ${ }^{3}$, Ahmad Armouti ${ }^{4}$, Ahmed Bayoumi ${ }^{5}$, Ezequiel Piccione ${ }^{1}$ \\ ${ }^{1}$ University of Nebraska Medical Center, College of Medicine, Department of Neurological Sciences \\ ${ }^{2}$ Mercy Hospital, Department of Neurology \\ ${ }^{3}$ University of Texas Medical Branch - Galveston, Department of Neurology \\ ${ }^{4}$ University of South Florida Morsani College of Medicine, Department of Neurology \\ ${ }^{5}$ Yale University, Department of Neurology
}

Mentor: Ezequiel Piccione

Program: Neurology

Type: Review/Meta-analysis

Background: In January 2020, the first case of Guillain Barre Syndrome (GBS) due to COVID-19 was documented in China. GBS is known to be postinfectious following several types of infections. Although causality can only be proven through large epidemiological studies, we intended to study this association by a thorough review of the literature.

Methods: We searched PubMed, EMBASE and Google scholar, and included all papers with English or Spanish full text and original data of patients with GBS and recent
COVID infection. Variables of interest were demographics, diagnostic investigations and the latency between arboviral and neurological symptoms. Further variables were pooled to identify GBS clinical and electrophysiological variants, used treatments and outcome. Certainty of GBS diagnosis was verified using Brighton criteria.

Results: We identified a total of 109 GBS cases. Nighty nine cases had a confirmed COVID-19 infection with an average age of 56.07 years. The average latency period between the arboviral symptoms and neurologic manifestations for confirmed COVID-19 cases was 12.2 days. The predominant GBS clinical and electromyography variants were the classical sensorimotor GBS and acute demyelinating polyneuropathy respectively. Forty cases required intensive care, 33 cases required mechanical ventilation, and 6 cases were complicated by death.

Conclusion: Studies on COVID-19-related GBS commonly reported sensorimotor demyelinating GBS with frequent facial palsy. The time between the onset of infectious and neurological symptoms suggests a post-infectious mechanism. Early diagnosis of GBS in COVID-19 patients is important as it might be associated with a severe disease course requiring intensive care and mechanical ventilation.

https://doi.org/10.32873/unmc.dc.gmerj.3.1.041

\title{
Cellular Dermatofibromas: Getting It Right the First Time Tyler D. Evans ${ }^{1}$, Erica B. Lee ${ }^{1}$, Adam V. Sutton ${ }^{1}$
}

${ }^{1}$ University of Nebraska Medical Center, College of Medicine, Department of Dermatology

\section{Mentor: Adam V. Sutton}

Program: Dermatology

Type: Review/Meta-analysis

Background: A dermatofibroma (DF) is a common, benign, skin lesion that accounts for approximately $3 \%$ of all skin specimens reviewed by dermatopathologists. A cellular dermatofibroma (CDF) is an aggressive variant that accounts for $5 \%$ of all cutaneous dermatofibromas. Given there are no established guidelines for CDF treatment, this review was aimed to review current treatment patterns in comparison to how we treat these lesions at our institution.

Methods: A PubMed literature search was performed using keyword 'cellular dermatofibroma.'

Results: There is no consensus on definitive treatments of CDF's. Clinically, it is similar to DF, but in many cases measures greater than $2 \mathrm{~cm}$ (DF is typically $<1 \mathrm{~cm}$ ). Though
CDF's have traditionally been thought to be of low malignant potential, cases of distant metastasis have been reported in the literature. There is a wide range of local recurrence rates after initial excision from 10\%-50\%. It's critically important to differentiate from dermatofibrosarcoma protuberans, a dermal neoplasm with intermediate malignant potential. Immunohistochemical (IHC) staining is the most beneficial in making this distinction. The spindle cells of CDF stain positive for factor XIIIa with CD34 staining the surrounding stroma and few cells around 
the periphery of the lesion. In comparison, DFSP stains diffusely positive for CD34 and negative for factor XIIIa. Additionally, CD 99 stains diffusely positive in CDF and negative in DFSP (Table 1).

Conclusion: Given the wide range of local recurrence $(10 \%$ to $50 \%)$, invasive behavior of the tumor, and potential of distant metastasis, comprehensive margin assessment (via Mohs Micrographic Surgery) represents an important treatment modality for select tumors. Specifically, CDF's located on the head and neck and neoplasms that have had previous wide local excision with positive margins are of particular concern. At our institution, we remove select CDF using comprehensive margin assessment, utilizing Hematoxylin \& Eosin staining along with Toluidine Blue staining. This technique allows for higher cure rates and tissue conservation.
Table 1.

Features differentiating dermatofiboma (DF), cellular dermatofibroma (CDF), and dermatofibrosarcoma protuberans (DFSP).

\begin{tabular}{|c|c|c|c|}
\hline & DF & CDF & DFSP \\
\hline Clinical & $\begin{array}{l}\text { Firm, skin colored to } \\
\text { hyperpigmented, papule, } \\
\text { plaque or nodule. } \\
\text { Dimpling with lateral } \\
\text { pressure. Commonly < } 1 \\
\text { cm in size. }\end{array}$ & $\begin{array}{l}\text { Firm, skin colored to } \\
\text { hyperpigmented, papule, } \\
\text { plaque or nodule. } \\
\text { Frequently, }>2 \mathrm{~cm} \text { in } \\
\text { diameter. }\end{array}$ & $\begin{array}{l}\text { Traditionally, a } \\
\text { hyperpigmented, slow growing, } \\
\text { nodule or plaque with irregular } \\
\text { nodularity on the trunk. }\end{array}$ \\
\hline Dermatopathology & $\begin{array}{l}\text { Proliferation of spindle } \\
\text { cells in storiform pattern } \\
\text { extending into the mid to } \\
\text { deep dermis. Collagen } \\
\text { trapping peripherally. }\end{array}$ & $\begin{array}{l}\text { Hypercellular proliferation } \\
\text { of spindle cells in fascicular } \\
\text { pattern extending into the } \\
\text { subcutaneous tissue with } \\
\text { smooth, pushing, border. }\end{array}$ & $\begin{array}{l}\text { Proliferation of spindle cells in } \\
\text { storiform pattern extending into } \\
\text { deep subcutaneous tissue with } \\
\text { irregular projections and in a } \\
\text { honeycomb pattern, encasing } \\
\text { adipocytes. }\end{array}$ \\
\hline $\mathrm{IHC}$ & $\begin{array}{l}\text { XIIIa (+), CD } 34(-), \text { CD } \\
99(+)\end{array}$ & $\begin{array}{l}\text { XIIla (+), CD } 34(+, \text { weakly, } \\
\text { of stroma and few cells on } \\
\text { periphery only) CD } 99(+)\end{array}$ & $\begin{array}{l}\text { XIla (-), CD } 34(+, \text { strong, } \\
\text { diffuse), CD } 99(-)\end{array}$ \\
\hline Recurrence Rate & $2 \%$ to $3 \%$ & $10 \%$ to $50 \%$ & $\begin{array}{l}\text { Up to } 60 \% \text { (varies based on } \\
\text { surgical margins and technique } \\
\text { used) }\end{array}$ \\
\hline Treatment: & Observation & Mohs Surgery & Mohs Surgery \\
\hline
\end{tabular}

\section{Intravascular B-Cell Lymphoma Presenting as Cortical Venous Thrombosis}

Praveen Hariharan 1 , Mridula Krishnan², Timothy Greiner ${ }^{3}$, Catalina Amador ${ }^{3}$, Marco Gonzalez-Castellon 1

${ }^{1}$ University of Nebraska Medical Center, College of Medicine, Department of Neurological Sciences

${ }^{2}$ University of Nebraska Medical Center, College of Medicine, Department of Internal Medicine, Division of Oncology and Hematology

${ }^{3}$ University of Nebraska Medical Center, College of Medicine, Department of Pathology and Microbiology

Mentor: Marco Gonzalez-Castellon, MD

Program: Neurology

Type: Case Report

Background: Intravascular B-cell lymphoma (IVBCL) is a rare hematological neoplasm presenting with diverse neurological symptoms including ischemic infarcts, hemorrhage and peripheral nervous system infiltration. Here, we present a case of IVBCL presenting as multifocal cortical venous thrombosis.

Case: A 59-year-old right-handed Guatemalan immigrant female presented with subacute onset of altered mental status, lethargy, dysarthria, transient left face and arm numbness, unintentional weight loss and poor appetite. Physical exam was remarkable for disorientation to time and place and absence of any focal neurological deficits. Labs remarkable for pancytopenia. A CT scan of the brain revealed two areas of hemorrhages. Magnetic resonance (MR) imaging of the brain showed edema surrounding hemorrhage. MR Venogram was obtained that revealed multifocal cortical vein thrombosis. Blackblood MR Angiogram showed vessel wall enhancement involving peripheral arteries and veins. Cerebrospinal fluid (CSF) studies revealed elevated protein and normal cell count. The malignancy screen was negative. Extensive infectious and inflammatory workup revealed latent syphilis. She developed bilateral lower extremity weakness with upgoing toes after 10 days of admission. MR Thoracic spine revealed T2 hyperintensities at the level of T10. A bone marrow biopsy revealed large, atypical B-cells in the lumina of sinusoids and skin biopsy demonstrated evidence of intravascular diffuse large B-cell lymphoma although peripheral smear was negative.

Conclusion: IVBCL is a rare extra-nodal diffuse large B-cell lymphoma subtype characterized by selective growth of B-cells within lumina of small vessels due to lack of CD29 that is critical for extravasation of lymphocytes. Neurological presentations are diverse and diagnosis could be delayed given a normal peripheral smear. One needs to maintain a high index of suspicion presenting with B-symptoms and ischemic or hemorrhagic strokes.

https://doi.org/10.32873/unmc.dc.gmerj.3.1.043 